\title{
Potential for entomopathogenic fungi to control Triatoma dimidiata (Hemiptera: Reduviidae), a vector of Chagas disease in Mexico
}

\author{
María Guadalupe Vázquez-Martínez ${ }^{[1]}$, Blanca Elva Cirerol-Cruz ${ }^{[1]}$, \\ José Luis Torres-Estrada ${ }^{[1]}$ and Mario Henry Rodríguez López ${ }^{[2]}$
}

[1].Centro Regional de Investigación en Salud Pública, Instituto Nacional de Salud Pública, Tapachula, Chiapas, México. [2]. Centro de Investigación sobre Enfermedades Infecciosas, Instituto Nacional de Salud Pública, Cuernavaca, Morelos, México.

\begin{abstract}
Introduction: The use of entomopathogenic fungi to control disease vectors has become relevant because traditional chemical control methods have caused damage to the environment and led to the development of resistance among vectors. Thus, this study assessed the pathogenicity of entomopathogenic fungi in Triatoma dimidiata. Methods: Preparations of $10^{8}$ conidia/ml of Gliocladium virens, Talaromyces flavus, Beauveria bassiana and Metarhizium anisopliae were applied topically on T. dimidiata nymphs and adults. Controls were treated with the $0.0001 \%$ Tween- 80 vehicle. Mortality was evaluated and recorded daily for 30 days. The concentration required to kill $50 \%$ of T. dimidiata $\left(\mathrm{LC}_{50}\right)$ was then calculated for the most pathogenic isolate. Results: Pathogenicity in adults was similar among B. bassiana, G. virens and T. flavus ( $>0.05)$ and differed from that in triatomine nymphs $(\mathrm{p}=0.009)$. The most entomopathogenic strains in adult triatomines were B. bassiana and G. virens, which both caused $100 \%$ mortality. In nymphs, the most entomopathogenic strain was B. bassiana, followed by G. virens. The native strain with the highest pathogenicity was $G$. virens, for which the $\mathrm{LC}_{50}$ for $T$. dimidiata nymphs was $1.98 \times 10^{8}$ conidia/ml at 13 days after inoculation. Conclusions: Beauveria bassiana and G. virens showed entomopathogenic potential in T. dimidiata nymphs and adults. However, the native G. virens strain presents a higher probability of success in the field, and G. virens should thus be considered a potential candidate for the biological control of triatomine Chagas disease vectors.
\end{abstract}

Keywords: Biological control. Chagas disease. Entomopathogenic fungi. Triatoma dimidiata.

\section{INTRODUCTION}

Chagas disease is one of the major neglected tropical diseases transmitted by insect vectors. It causes high morbidity and mortality, reaching levels comparable to those observed for human immunodeficiency virus/acquired immunodeficiency syndrome (HIV/AIDS) in the Latin American region ${ }^{1}$. However, the current extent of globalization of the disease is evident in the 300,000 to 1,000,000 cases present in the United States of America $^{2}$, and the disease has expanded into Canada, Europe, Australia and $\mathrm{Japan}^{3}$, as well. Chagas disease is caused by the protozoan parasite Trypanosoma cruzi and is transmitted by hematophagous bugs of the order Hemiptera, family Reduviidae, subfamily Triatominae. Currently, 147 species are included in this group ${ }^{4,5}$, but species from only three genera, Triatoma,

\footnotetext{
Address to: Dra. María Guadalupe Vázquez-Martínez. CRISP/INSP. 19 Poniente y $4^{\mathrm{a}}$. Av. Norte. Colonia Centro, CP 30700 Tapachula, Chiapas, México. Phone: 52962626 2219; Fax: 529626265782

e-mail: mguadalu@insp.mx

Received 18 August 2014

Accepted 24 November 2014
}

Rhodnius and Panstrongylus, are widely distributed in endemic areas in the Americas, from Mexico through Argentina and Chile $^{6}$, and serve as the main vectors of T. cruzi in domestic animals and humans.

In Mexico, Chagas disease has been reported in all 31 states and in the capital city ${ }^{7}$. Thirty-three triatomine species have been identified, of which 28 are endemic and 22 have been reported to be infected with $T$. $\mathrm{cruzi}^{8-12}$. Based on their domiciliary habits, the most important of these are Triatoma longipennis, Triatoma mazzotti, Triatoma pallidipennis, Triatoma picturata, Triatoma barberi, Triatoma mexicana, Triatoma gerstaeckeri and Triatoma dimidiata ${ }^{7,13}$. Triatoma dimidiata has a wide geographical distribution and can be found from Mexico to Northern South America; it is one of the most important vectors of Chagas disease in Central America and southern Mexico ${ }^{6,14}$.

No vaccine is currently available for Chagas disease, and the existing drug treatment has limited effectiveness and undesirable side effects; thus, anti-vectorial interventions are the main strategy for the control of this disease. These interventions include improvements in housing conditions and vector control through indoor insecticide spraying ${ }^{15}$ using several synthetic carbamates, organophosphates and pyrethroids ${ }^{16-18}$. However, in addition to adverse environmental effects of these substances, an increase in the numbers of field vector populations resistant 
to insecticides has been documented, making insecticide-based control strategies inefficient ${ }^{17-23}$. Thus, new alternatives are urgently needed for use in integrated vector control strategies.

Several experiments have documented the efficacy of entomopathogenic fungi, such as Beauveria bassiana and Metarhizium anisopliae, in the control of Chagas disease vectors under laboratory ${ }^{24-28}$ and field conditions ${ }^{29-32}$. The first barrier to the penetration of contact insecticides is the insect cuticle, and an increase in the thickness of the Triatoma infestans cuticle was found to be associated with the resistance of this insect to pyrethroids. A strain of $B$. bassiana adapted to grow more easily on insect-like hydrocarbons used in attraction-infection traps, which combine $\mathrm{CO}_{2}$ with the fungus, has been reported to cause $52.4 \%$ mortality in pyrethroid-resistant insects in experimental houses and rural human dwellings. This indicates that the capacity of entomopathogenic fungi to degrade the cuticle of insects is an advantage that could be exploited for the control of insecticide-resistant triatominae ${ }^{29}$.

Environmental factors may affect the efficiency of these fungi ${ }^{26}$, but native fungal strains, which are adapted to local conditions, may exhibit better performance. We have isolated several entomopathogenic fungal strains from communities near Tapachula, Chiapas, in southern Mexico, with the purpose of developing bioinsecticides for the control of disease vector insects. This study assessed the pathogenicity of native Gliocladium virens (Miller) Giddens and Foster and Talaromyces flavus (Klöcker) Stolk and Samson in T. dimidiata nymphs and adults, compared with $B$. bassiana (Balsamo) Vuillemin and M. anisopliae (Metschnikoff) Sorokin, which are pathogenic fungi used in the control of agricultural plagues.

\section{METHODS}

\section{Triatomines}

Triatoma dimidiata nymphs and adults were collected in 17 communities in the foothills near Tapachula, Chiapas, Mexico $\left(15^{\circ} 03^{\prime}-14^{\circ} 13^{\prime} \mathrm{N}\right.$ and $\left.92^{\circ} 26^{\prime}-92^{\circ} 29^{\prime} \mathrm{W}\right)$ via active searches in peridomestic sites. The collected insects were divided into two groups; one group was used for pathogenicity bioassays, while the other group was reared in the laboratory at $27 \pm 1^{\circ} \mathrm{C}$ under $70 \pm 2 \%$ relative humidity. First-generation insects raised in the laboratory were used to determine lethal concentrations of the studied fungi. One week before each bioassay, triatomines were fed with rabbit blood. Two days before the bioassay, all triatomines were disinfected by a two-minute treatment with a $0.5 \%$ sodium hypochlorite solution. The insects were washed three times with sterile triple-distilled water and dried.

\section{Fungal strains}

Four fungal strains were used in the bioassays. Beauveria bassiana LBIH-048 was isolated from the coffee bug of the sorghum pest Oebalus mexicana Sailer, and M. anisopliae sensu lato LBIH-033 was isolated from white grubs of Phyllophaga spp. These fungal strains were obtained from the collection of the Center for Research and Advanced Studies (CINVESTAV,
Irapuato, Mexico). The native strains T. flavus LBIH-111 and G. virens LBIH-116 were isolated from Anopheles albimanus larval breeding sites on the coastal plain of Chiapas, Mexico $\left(14^{\circ} 43^{\prime}-14^{\circ} 52^{\prime} \mathrm{N}\right.$ and $\left.92^{\circ} 26^{\prime}-92^{\circ} 33^{\prime} \mathrm{W}\right)$ in 2007 and were obtained from the collection of entomopathogenic fungi of the Laboratory of Biocontrol of Disease Vector Insects of the National Institute of Public Health (INSP, Chiapas, Mexico). All of the fungal strains were deposited in the collection of entomopathogenic fungi (REDBIO) at the laboratory of bioinsecticides at CINVESTAV in Irapuato, Mexico.

The fungi were cultured on Sabouraud dextrose agar medium (SDA, Bioxon ${ }^{\circledR}$, Becton Dickinson de Mexico) at $27 \pm 1^{\circ} \mathrm{C}$ until conidia were visible, which occurred within approximately 21 days. Conidial suspensions were prepared in sterile distilled water with $0.0001 \%$ Tween- 80 . The viability of the fungi was assessed by measuring conidial germination on SDA medium under optimal conditions ${ }^{33}$. Conidial suspensions demonstrating more than $90 \%$ germination were used in the bioassays. Conidial concentrations were estimated using a Neübauer camera (Hausser Scientific).

\section{Pathogenicity bioassays}

Groups of field-collected insects, consisting of ten nymphs (different instars) and ten adults of $T$. dimidiata, were treated via topical application of 3 and $5 \mathrm{ml}$, respectively, of a fungal suspension consisting of $10^{8}$ conidia $/ \mathrm{ml}$ of $B$. bassiana, G. virens, T. flavus, or M. anisopliae in $0.0001 \%$ Tween- 80 ; the fungal suspension was placed on the surface of the cuticle using a micropipette ${ }^{33}$. Control insects were treated with $0.0001 \%$ Tween- 80 without conidia. Treated triatomines were placed in containers within an environmental chamber (Thermo Electron Corporation Model 818 ) at $27 \pm 2^{\circ} \mathrm{C}$ and $75 \pm 5 \%$ relative humidity $(\mathrm{RH})$ with a $10 \mathrm{~h}$ light:14h dark photoperiod. The deaths of insects were recorded daily for 30 days after treatment. Each bioassay consisted of 10 insects per fungal strain and 10 insects in a control group. The number of repetitions of each assay varied from three to six, depending on the availability of insects.

The percentage of insects exhibiting spore production was obtained using a stereo microscope to quantify the number of dead individuals with spores in relation to the dead individuals without spores. Mortality for each fungal treatment was measured as the average time (days) between a fungal application and the death of an insect; only triatomines with spores were included in the counts.

\section{Lethal concentration $\left(\mathrm{LC}_{50}\right)$}

Given the high pathogenicity of G. virens observed in the bioassays using nymphs and adults, we chose to evaluate the concentration of this fungus required to kill $50 \%\left(\mathrm{LC}_{50}\right)$ of T. dimidiata nymphs. Six concentrations, $5 \times 10^{8}, 1 \times 10^{8}, 5 \times 10^{7}$, $1 \times 10^{7}, 5 \times 10^{6}$ and $1 \times 10^{6}$ conidia/ml in $0.0001 \%$ Tween- 80 , were tested on groups of 20 insects, with three repetitions for each conidial concentration and for a control group, for a total of 420 triatomines. The control groups were treated with $0.0001 \%$ Tween- 80 solution without conidia. Daily observations of mortality were carried out for 30 days, as indicated above. 


\section{Statistical analysis}

A generalized linear model (GLM) and variance analysis with multiple mean comparisons using the least significant difference (LSD) test were used to compare mortality, the percentages of insects exhibiting spore formation and the average number of days until death in triatomines with different treatments ${ }^{34}$. The deaths recorded with different fungal concentrations were subjected to probit analysis (EPA, Version 1.5). The mortality curves obtained for the different concentrations of the selected fungal isolate were adjusted to sigmoid curves, for which the results of goodness-of-fit tests were verified using chi-squared tests. The curves were then linearized by probit transformation, and the $\mathrm{LC}_{50}$ of the population was calculated using a regression equation, assuming normality ${ }^{35}$.

\section{RESULTS}

\section{Pathogenicity bioassays}

The fungus $B$. bassiana and the native strain $G$. virens exhibited the highest pathogenicity in $T$. dimidiata nymphs, resulting in $73.3 \%$ and $35.7 \%$ mortality, respectively, at 30 days after treatment. For the M. anisopliae and T. flavus strains, nymph mortality was $20 \%$ and $16.6 \%$, respectively. No deaths were recorded among the controls (Figure 1).

It was observed that lower pathogenicity of the fungal strains was related to lower levels of spore formation. The rate of spore-producing infections in dead nymphs was $70 \%$ for G. virens, $66.7 \%$ for B. bassiana and $25 \%$ for M. anisopliae. The T. flavus strain did not result in spore-producing infections.
Similarly, B. bassiana, which exhibited the greatest pathogenicity, caused mortality more rapidly, as well; the first dead nymph was detected nine days after conidial treatment. Gliocladium virens and $M$. anisopliae caused nymphs to die after an average of 17 days, and T. flavus caused nymphs to die after 21 days.

Gliocladium virens, the native fungal strain, and B. bassiana caused $100 \%$ mortality in $T$. dimidiata adults. Talaromyces flavus had a $75 \%$ mortality rate, and $M$. anisopliae had a $25 \%$ mortality rate (Figure 2). Beauveria bassiana caused adult triatomines to die within 13.6 days, on average, and G. virens caused death in only 8.3 days. For T. flavus and M. anisopliae, adult triatomine mortality was observed after an average of 16 and 24 days, respectively. Fungal development on dead adults was examined; viable conidia were detected on the surface of $88.8 \%$ and $50 \%$ of cadavers treated with B. bassiana and G. virens (Figure 3), respectively.

The results obtained from the pathogenicity bioassays revealed significant differences among the fungi in terms of the mortality of $T$. dimidiata nymphs and adults compared with the control group. Mortality in the control group was $0 \%$ for nymphs and $10 \%$ for adults. The pathogenicity of the fungal strains in adults was similar among B. bassiana, G. virens and T. flavus $(\mathrm{p}>0.05)$ and different from those in nymphs $(\mathrm{F}=1.77$; d.f. $=53 ; \mathrm{p}=0.009)$. Significant differences in spore formation were observed among the four tested strains $(\mathrm{F}=1.84 ;$ d.f. $=41 ; \mathrm{p}=0.04)$, whereas no significant difference in the average number of days required to kill triatomines was observed among the strains ( $\mathrm{F}=0.47$; d.f. $=28 ; \mathrm{p}=0.95)$.

In the pathogenicity bioassays, $G$. virens exhibited the highest pathogenicity (mortality rate, sporulation and time to kill) in T. dimidiata in both adults and nymphs.

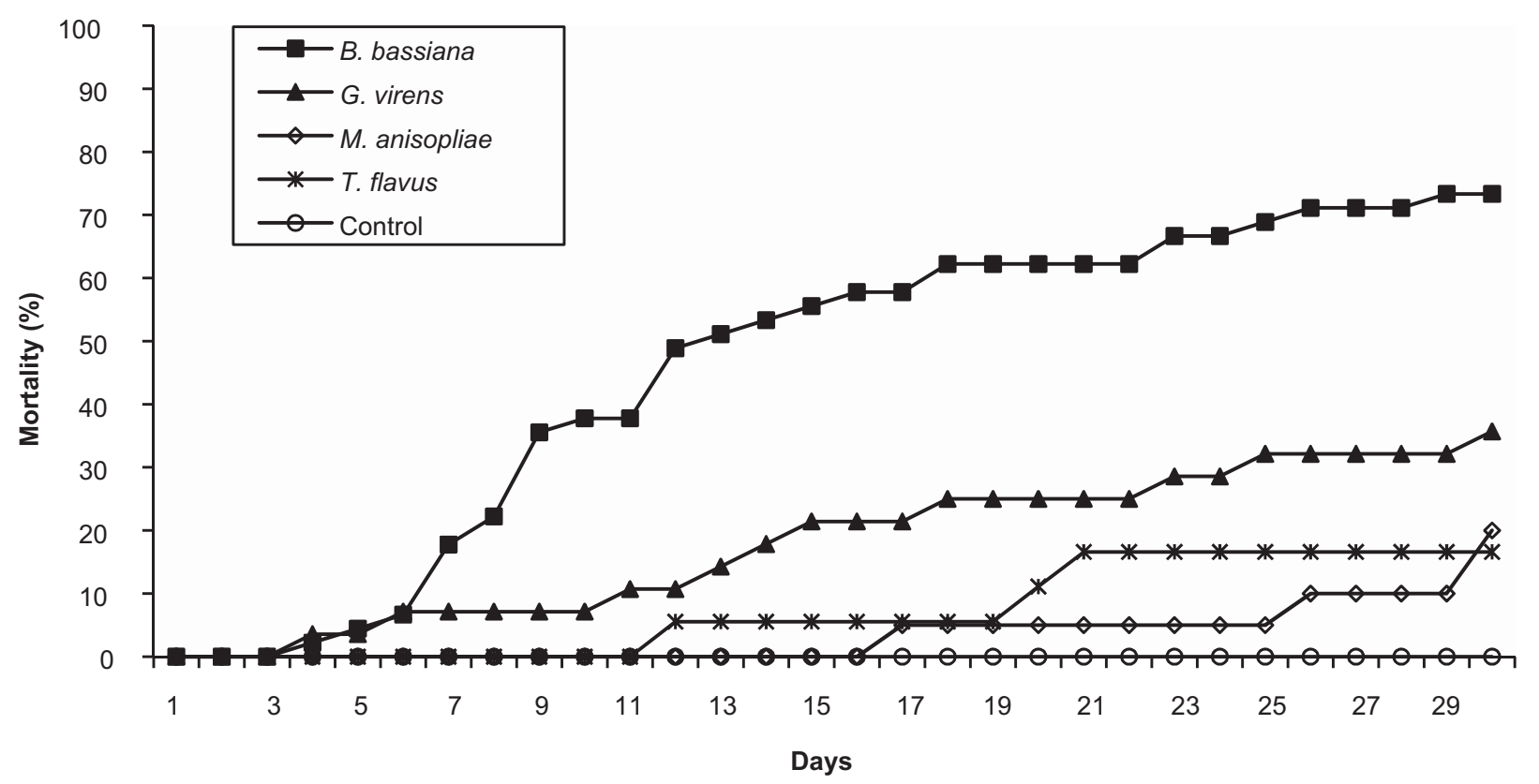

FIGURE 1 - Cumulative mortality of Triatoma dimidiata nymphs topically inoculated with fungal suspensions containing $10^{8}$ conidia/ ml of B. bassiana, G. virens, M. anisopliae and T. flavus. B.: Beauveria; G.: Gliocladium; M.: Metarhizium; T.: Talaromyces. 


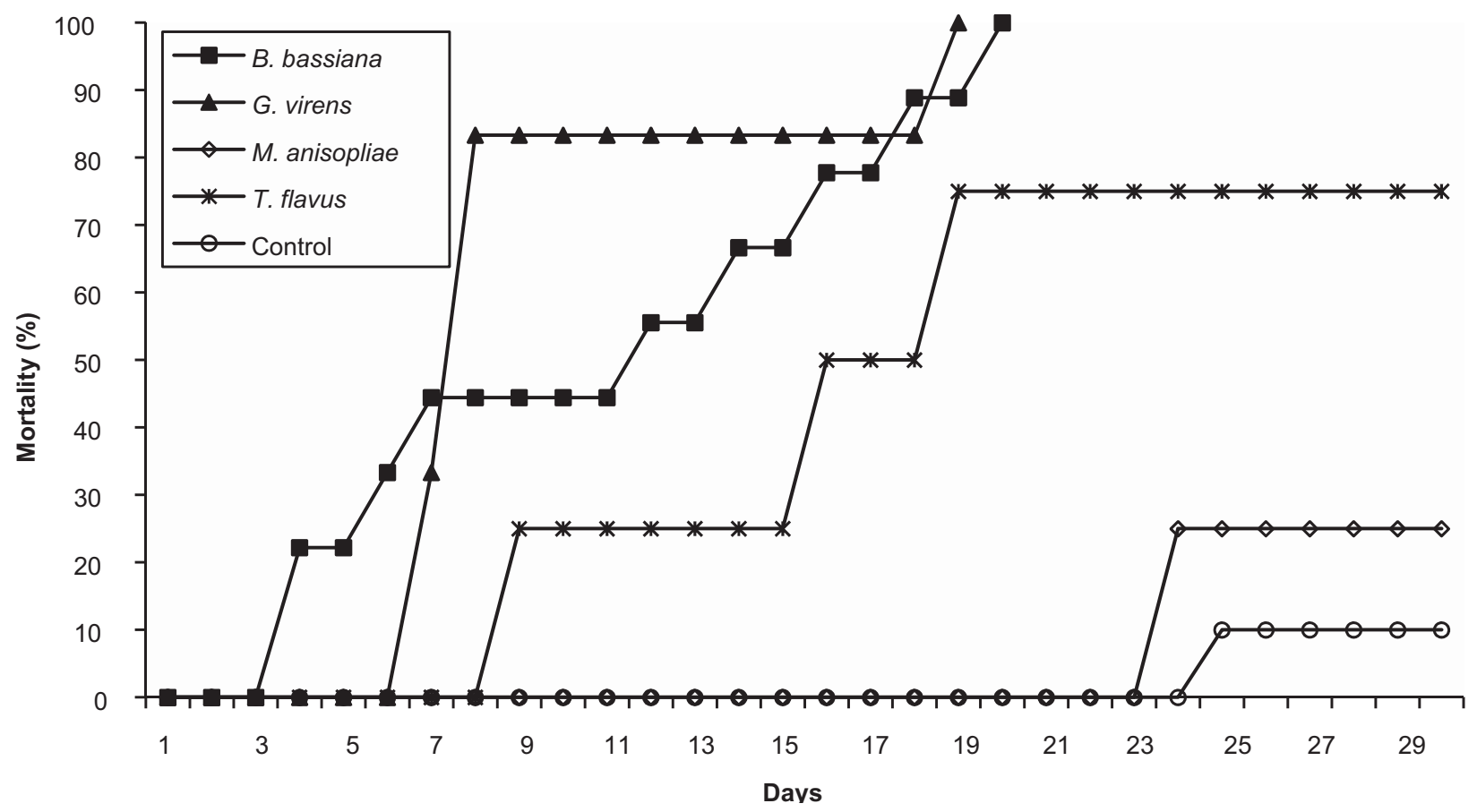

FIGURE 2 - Cumulative mortality of Triatoma dimidiata adults topically inoculated with fungal suspensions containing $10^{8}$ conidia/ml of B. bassiana, G. virens, M. anisopliae and T. flavus. B.: Beauveria; G.: Gliocladium; M.: Metarhizium; T.: Talaromyces.

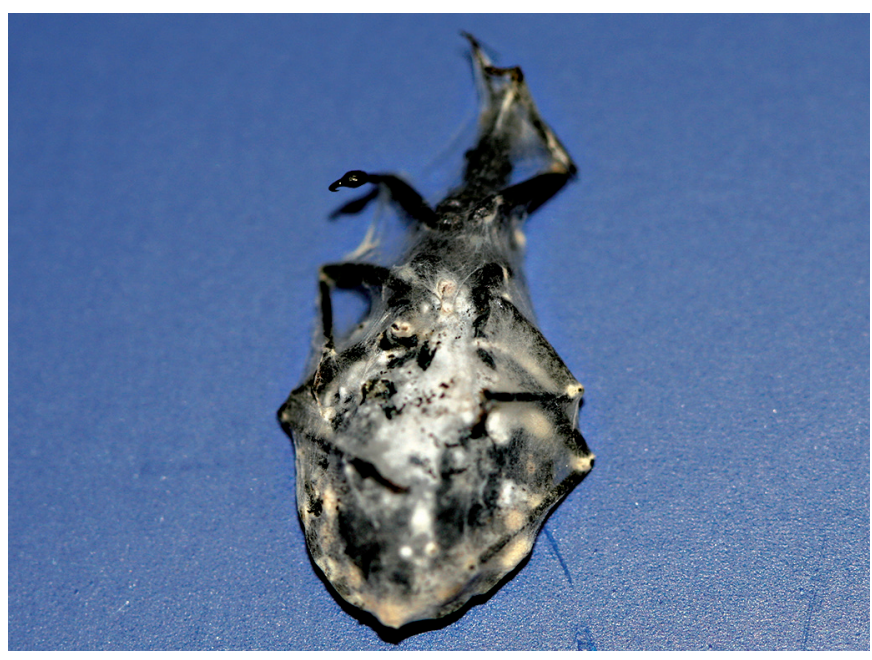

FIGURE 3 - Triatoma dimidiata adult infected with Gliocladium virens.

\section{Lethal concentration $\left(\mathrm{LC}_{50}\right)$}

In the bioassays using different concentrations of $G$. virens conidia, the mortality rate among $T$. dimidiata nymphs increased as the concentration of conidia increased. The highest concentration $\left(5 \times 10^{8}\right.$ conidia $\left./ \mathrm{ml}\right)$ resulted in $58 \%$ mortality after 13 days and $80 \%$ mortality at 30 days after inoculation.

Deaths recorded after 13 days were used to determine the $\mathrm{LC}_{50}$ using the probit method. A calculated chi-squared value of $\chi^{2=3.039}$ was obtained, and a heterogeneity test revealed no significant heterogeneity $(\mathrm{p}>0.05)$. Using adjusted values for the observed responses, the $\mathrm{LC}_{50}$ of $G$. virens in T. dimidiata nymphs was calculated to be $1.98 \times 10^{8}$ conidia/ml $(1.10-4.68,95 \% \mathrm{CI})$.

\section{DISCUSSION}

In this study, $B$. bassiana and the native strain $G$. virens caused the highest pathogenicity in $T$. dimidiata nymphs and adults. Adults were more susceptible to fungal infection than nymphs, most likely because the nymphs lost their conidia during molting after topical inoculation. The triatomines used in this bioassay were collected in the field, and the timing of molting in nymphs therefore could not be controlled. Rocha et al. ${ }^{36}$ investigated mass-reared laboratory colonies of Rhodnius spp. (third-instar nymphs) treated with Lecanicillium psalliotae, Paecilomyces lilacinus and Pochonia chlamydosporia and calculated that the time until $50 \%$ of all infected nymphs died $\left(\mathrm{LT}_{50}\right)$ was 12.8 days for Rhodnius neglectus infected with P. lilacinus and 22.6 days for $R$. robustus infected with L. psalliotae. In the present study, G. virens killed $50 \%$ of the exposed population of $T$. dimidiata in 11 days, which is a shorter period of time than was observed by Rocha et al. ${ }^{36}$, regardless of the fact that the insects were collected from the field.

It was previously reported that treatment with $1.0 \times 10^{7}$ conidia/ml of B. bassiana resulted in $100 \%$ mortality for T. infestans adults at 15 days after inoculation ${ }^{28}$. Triatoma infestans mortality following treatment with $B$. bassiana $\mathrm{Bb} 10$ conidia grown on CAM medium was $100 \%$ in nymphs, and the $\mathrm{LT}_{50}$ in nymphs was 7.1 days. In adults, mortality due to 
B. bassiana $\mathrm{Bb} 10$ conidia was $100 \%$, with an $\mathrm{LT}_{50}$ of 4.8 days ${ }^{26}$. These findings suggest that our strain of $B$. bassiana is less pathogenic than strains investigated by others, as our strain causes less mortality over a longer time. These differences could be attributed to variations in triatomine susceptibility. However, little information is available regarding the factors affecting host susceptibility to entomopathogenic fungi. One important factor is the degradation and/or penetration of the initial barrier that must be overcome for successful infection to occur, particularly in relation to the hydrocarbons that constitute the insect epicuticle. The composition of surface lipids has profound consequences that affect the ecological and behavioral characteristics of insects ${ }^{37}$. However, it is more likely that low pathogenicity is an intrinsic characteristic of the fungal strain that we studied ${ }^{27}$.

The $\mathrm{LC}_{50}$ for $G$. virens infections of $T$. dimidiata nymphs was $1.98 \times 10^{8}$ conidia/ml at 13 days after treatment; this value is higher than those observed in another study using third-instar T. infestans nymphs, for which the values of $\mathrm{LC}_{50}$ were $7.1 \times 10^{5}$ for the B. bassiana isolate CG 14 and $4.3 \times 10^{6}$ conidia $/ \mathrm{ml}$ for the $M$. anisopliae isolate CG $491^{38}$.

A concentration of $2.4 \times 10^{6}$ conidia/ $/ \mathrm{cm}^{2}$ of $B$. bassiana was required to kill $50 \%$ of $T$. infestans third-instar nymphs at 25 days after inoculation when insects were continuously exposed to conidia. The $\mathrm{LC}_{50}$ was significantly higher $\left(2.0 \times 10^{7}\right.$ conidia/ $\mathrm{cm}^{2}$ ) when insects were exposed for $1 \mathrm{~h}$ to treated filter paper ${ }^{39}$. In another study, a fungal suspension was used to inoculate $T$. infestans adults; insects were individually submerged in a 5 -ml suspension of $B$. bassiana at $10^{7}$ conidia/ml for 7 seconds $^{28}$. The median survival time of $T$. infestans adults inoculated in this fashion was 6.7 days, and $100 \%$ mortality occurred by 15 days post treatment ${ }^{28}$. In our study, treatment of $T$. dimidiata adults with a topical application of a suspension of $G$. virens resulted in $100 \%$ mortality in an average of 8.3 days, a shorter time than has been reported previously. No previous study has reported G. virens pathogenicity in triatomines; until now, it has only been considered to be an antagonist fungus ${ }^{40}$. In recently reported pathogenicity bioassays, the $\mathrm{LC}_{50}$ of $G$. virens in An. albimanus larvae was found to be $3.3 \times 10^{5}$ conidia/ml in early larval instars and $3.5 \times 10^{6}$ conidia/ml in late instars ${ }^{41}$. These findings indicate that these insects are more susceptible to $G$. virens compared with $T$. dimidiata.

In preliminary field tests ${ }^{42}$, the mortality of $T$. infestans treated with unformulated B. bassiana conidia was lower and occurred more slowly in comparison with laboratory tests ${ }^{38}$. Gliocladium virens shows greater potential for use in control strategies because, in addition to the fact that native strains are most likely to be successful in the field, this fungus is easily produced in laboratory using artisanal methods ${ }^{43}$. However, further studies are necessary to establish adequate fungal formulations and to determine the most effective method of application under field conditions.

The invasion of domestic and peridomestic triatomines is a major difficulty for Chagas disease control. Periodic seasonal dispersion of adult $T$. dimidiata from sylvatic and peridomestic habitats into houses during the hottest, driest months of the year has been observed in Yucatan, Mexico. While a higher percentage of adults were captured in intradomiciliary locations, the majority of nymphs were collected in peridomiciliary locations. Similar infection rates with $T$. cruzi in insects collected indoors and outdoors ${ }^{44}$ highlight the importance of peridomiciliary insects in the risk of transmission of $T$. cruzi to humans ${ }^{45}$. Taking into account environmental factors such as temperature and relative humidity, it has been recommended that B. bassiana be applied peridomestically during the rainy season to control peridomestic $T$. sordida and that insecticides be applied during dry periods; a combination of both strategies during both seasons has also been suggested ${ }^{46}$. These strategies could be considered for use with our strain of G. virens, a native strain adapted to the environment of southern Chiapas ${ }^{41}$. However, further studies under field conditions are required in the various habitats of $T$. dimidiata to determine appropriate fungal formulations and the most effective application methods, as well residual effects on this insect population.

Although entomopathogenic fungi are more persistent in the environment than other microbial insecticides and convert dead insects into new inoculum sources ${ }^{47}$, specific environmental conditions are necessary for fungal germination. This may explain why T. flavus did not grow in treated insects in our study. Low humidity has been reported to be responsible for the failure of $B$. bassiana to emerge from the corpses of treated T. infestans ${ }^{38,39}$.

The rates of $G$. virens infection that were observed (70\% in dead nymphs and $50 \%$ in dead adults) are encouraging in the context of biological control because all contaminated carcasses exhibited viable conidia. This ensures that under field conditions, the infection could be transmitted to healthy insects via direct passive transfer facilitated by the social behavior of these insects or could be spread by wind. Accordingly, the aggregation of $T$. infestans in small nests facilitates contact between insects and contributes to the transmission of $B$. bassiana in laboratory trials ${ }^{29}$. In addition, under field conditions, dry B. bassiana conidia formulations remained viable $(88.63 \%)$ after three months ${ }^{29}$, and its virulence against first and third T. infestans instars did not change significantly for up to 5 months under similar conditions ${ }^{48}$.

Because $G$. virens is pathogenic in T. dimidiata nymphs and adults and because a native strain is most likely to be effective under local field conditions, this species of fungus should be considered a good candidate for the biological control of triatomine vectors of Chagas disease in southern Mexico.

\section{ACKNOWLEDGMENTS}

We thank Dr. Jorge E. Ibarra Rendón, Center for Research and Advanced Studies in Irapuato (CINVESTAV-Irapuato) for his donation of Beauveria bassiana and Metarhizium anisopliae isolate; to Olga R. Gálvez, Daniel Sánchez García, and Luis A. Cisneros for technical support. 


\section{CONFLICT OF INTEREST}

The authors declare that there is no conflict of interest.

\section{FINANCIAL SUPPORT}

This study was supported by the National Council of Science and Technology (CONACYT) Project No. 13972, FOSSISCONACYT.

\section{REFERENCES}

1. Hotez PJ, Dumonteil E, Woc-Colburn L, Serpa JA, Bezek S, Edwards MS, et al. Chagas Disease: "The New HIV/AIDS of the Americas". PLoS Negl Trop Dis 2012; 6:e1498.

2. Bern C, Kjos S, Yabsley MJ, Montgomery SP. Trypanosoma cruzi and Chagas' disease in the United States. Clin Microbiol Rev 2011; 24:655-681.

3. Gascon J, Bern C, Pinazo MJ. Chagas disease in Spain, the United States, and other non-endemic countries. Acta Trop 2010; 115:22-27.

4. Costa J, Correia NC, Neiva VL, Goncalves TCM, Felix M. Revalidation and redescription of Triatoma brasiliensis macromelasoma Galvão, 1956 and an identification key for the Triatoma brasiliensis complex (Hemiptera: Reduviidae: Triatominae). Mem Inst Oswaldo Cruz 2013; 108:785-789.

5. Gonçalves TCM, Teves-Neves SC, Santos-Mallet JR, Carbajalde-la-Fuente AL, Lopes CM. Triatoma jatai sp. nov. in state of Tocantins, Brazil (Hemiptera: Reduviidae: Triatominae). Mem Inst Oswaldo Cruz 2013; 108:429-437.

6. Organización Mundial de la Salud. Control de la Enfermedad de Chagas, Segundo informe del comité de expertos de la OMS. Ginebra: OMS; 2002. p. 75-88.

7. Cruz-Reyes A, Pickering-López JM. Chagas disease in Mexico: an analysis of geographical distribution during the past 76 years A review. Mem Inst Oswaldo Cruz 2006; 101:34-354.

8. Lent H, Wygodzinsky P. Revision of the Triatominae (Hemiptera: Reduviidae) and their significance as vectors of Chagas' disease. Bull Am Mus Nat Hist 1979; 163:123-520.

9. Zárate LG, Zárate RJ. A checklist of the Triatominae (Hemiptera: Reduviidae) of Mexico. Int J Entomol 1985; 27:102-127.

10. Vidal-Acosta V, Ibáñez-Bernal S, Martínez-Campos C. Infección natural de chinches Triatominae con Trypanosoma cruzi asociadas a la vivienda humana en México. Salud Publica Mex 2000; 42:496-503.

11. Galvão C, Carcavallo RU, Rocha DS, Jurberg J. A checklist of the current valid species of the subfamily Triatominae Jeannel, 1919 (Hemiptera: Reduviidae) and their geographical distribution, with nomenclatural and taxonomic notes. Zootaxa 2003; 202:1-36.

12. Salazar-Schettino MP, Rojas-Wastavino GE, Cabrera-Bravo $M$, Bucio-Torres MI, Martínez-Ibarra JA, Monroy-Escobar MC, et al. Revisión de 13 especies de la familia Triatominae (Hemiptera: Reduviidae) vectores de la enfermedad de Chagas en México. J Selva Andina Res Soc 2010; 1:57-80.

13. Bargues M, Klisiowicz D, Gonzalez F, Ramsey J, Monroy C, Ponce C, et al. Phylogeography and genetic variation of Triatoma dimidiata, the main Chagas disease vector in Central America, and its position within the genus Triatoma. PLoS Negl Trop Dis 2008; 2:1-19.

14. Guhl F. Enfermedad de Chagas: Realidad y perspectivas. Rev Biomedica 2009; 20:228-234.
15. Vazquez-Prokopec G, Spillmann C, Zaidenberg M, Kitron U, Gürtler RE. Cost-effectiveness of Chagas disease vector control strategies in Northwestern Argentina. PLoS Negl Trop Dis 2009; 3:e363.

16. Gualtieri J, Nelson M, Cichero J. Present and perspectives of the chemical control. In: Carcavallo R, Rabinovich J, Tonn R, editors. Factores biológicos y ecológicos en la Enfermedad de Chagas. Tomo II. Buenos Aires: Ministerio de Salud y Acción Social de la Nación; 1985. p. 319-329.

17. Vassena CV, Piccollo MI, Zerba EN. Insecticide resistance in Brazilian Triatoma infestans and Venezuelan Rhodnius prolixus. Med Vet Entomol 2000; 14:51-55.

18. Picollo MI, Vassena C, Santo-Orihuela P, Barrios S, Zaidemberg M, Zerba E. High resistance to pyrethroid insecticides associated with ineffective field treatments in Triatoma infestans (Hemiptera: Reduviidae) from Northern Argentina. J Med Entomol 2005; 42:637-642.

19. Vassena CV, Picollo MI. Monitoreo de resistencia a insecticidas en poblaciones de campo de Triatoma infestans y Rhodnius prolixus, insectos vectores de la enfermedad de Chagas. Retel 2003; 3:21.

20. Alarico AG, Romero N, Hernández L, Catalá S, Gorla D. Residual effect of a micro-encapsulated formulation of organophosphates and piriproxifen on the mortality of deltamethrin resistant Triatoma infestans populations in rural houses of the Bolivian Chaco region. Mem Inst Oswaldo Cruz 2010; 105:752-756.

21. Lardeux F, Depickère S, Duchon S, Chavez T. Insecticide resistance of Triatoma infestans (Hemiptera, Reduviidae) vector of Chagas disease in Bolivia. Trop Med Int Health 2010; 15:1037-1048.

22. Roca AG, Mougabure CG, Germano M, Santo OP, Rojas CM, Noireau F, et al. Susceptibility of sylvatic Triatoma infestans from Andean valleys of Bolivia to deltamethrin and fipronil. J Med Entomol 2011; 48:828-835.

23. Depickère S, Buitrago R, Siñani E, Baune M, Monje M, Lopez R, et al. Susceptibility and resistance to deltamethrin of wild and domestic populations of Triatoma infestans (Reduviidae: Triatominae) in Bolivia: new discoveries. Mem Inst Oswaldo Cruz 2013; 107: 1042-1047.

24. Romaña CA, Fargues J. Relative susceptibility of different stages of Rhodnius prolixus to the entomopathogenic hyphomycete Beauveria bassiana. Mem Inst Oswaldo Cruz 1992; 87:363-368.

25. Juárez MP, Crespo R, Calderón-Fernández G, Lecuona RE, Cafferata LFR. Characterization and carbon metabolism in fungi pathogenic to Triatoma infestans, a chagas disease vector. J Invertebr Pathol 2000; 76:198-207.

26. Lecuona RE, Edelstein JD, Berretta MF, La Rossa FR, Arcas JA Evaluation of Beauveria bassiana (hyphomycetes) strains as potential agents for control of Triatoma infestans (Hemiptera: Reduviidae). J Med Entomol 2001; 38:172-179.

27. Melgar S, Landaverde P, Dardón M, Enriquez E, Chanquín S Selección de virulencia y caracterización genética de cepas guatemaltecas de Beauveria bassiana y Metarhizium anisopliae, para el control del insecto transmisor de la enfermedad de Chagas, Triatoma dimidiata. DIGI - USAC, Editorial Limusa; 2004. p. 78-82.

28. Marti G, Scorsetti A, Siri A, López C. Isolation of Beauveria bassiana (Bals.) Vuill. (Deuteromycotina: Hyphomycetes) from the Chagas disease vector, Triatoma infestans (Hemiptera: Reduviidae) in Argentina. Mycopathologia 2005; 159:389-391.

29. Pedrini N, Mijailovsky SJ, Girotti JR, Stariolo R, Cardozo RM, Gentile A, et al. Control of pyrethroid-resistant chagas disease vectors with entomopathogenic fungi. PLoS Negl Trop Dis 2009; 3:e434.

30. Luz C, Silva IG, Magalhaes BP, Cordeiro C, Tigano MS. Control of Triatoma infestans (Klug) (Reduviidae: Triatominae) with Beauveria bassiana (Bals.) Vuill.: Preliminary assays on 
formulation and application in the field. An Soc Entomol Brasil 1999; 28:101-110.

31. Luz C, Rocha L, Nery GV, Magalhaes BP, Tigano MS. Actividad of oil-formulated Beauveria bassiana against Triatoma sordida in peridomestic areas in central Brazil. Mem Inst Oswaldo Cruz 2004; 99:211-218.

32. Forlani L, Pedrini N, Juarez MP. Contribution of the horizontal transmission of the entomopathogenic fungus Beauveria bassiana to the overall performance of a fungal powder formulations against Triatoma infestans. Res Rep Trop Med 2011; 2:135-140.

33. Butt TM, Goettel MS. Bioassays of entomogenous fungi. In: Navon A, Ascher KR, editors. Bioassays of entomopathogenic microbes and nematodes. Wallingford, UK: CAB International; 2000. p. 141-196.

34. Statistical Analysis System (SAS). StatView by SAS Windows version. SAS Institute Inc: Cary (North Caroline); 2003.

35. World Health Organization (WHO). Guidelines for laboratory and field testing of mosquito larvicides. WHO/CDS/WHOPES/ GCDPP/2005.13; 2005.

36. Rocha LFN, Silva IG, Luz CH. Activity of some hypocrealean fungi collected in a Cerrado ecosystem against Rhodnius spp. (Hemiptera: Reduviidae) under laboratory conditions. Acta Trop 2011; 118: 63-66.

37. Pedrini N, Ortiz-Urquiza A, Huarte-Bonnet C, Zhang S, Keyhani NO. Targeting of insect epicuticular lipids by the entomopathogenic fungus Beauveria bassiana: hydrocarbon oxidation within the context of a host-pathogen interaction. Front Microbiol 2013; 4:24.

38. Luz C, Tigano MS, Silva IG, Cordeiro CMT, Aljanabi SM. Selection of Beauveria bassiana and Metarhizium anisopliae isolates to control Triatoma infestans. Mem Inst Oswaldo Cruz 1998; 93:839-846.

39. Luz C, Silva I, Magalhaes BP, Cordeiro CM, Tigano M. Control of Triatoma infestans (Klug) (Reduviidae: Triatominae) with Beauveria bassiana (Bals.) Vuill.: preliminary assays on formulation and application in the field. An Soc Entomol Brasil 1999; 28:101-110.
40. Burguess D, Bretag T, Keane P. Biocontrol of seedborne Botrytis cinerea in chickpea with Gliocladium roseum. Plant Pathol 1997; 46:298-305.

41. Vázquez-Martínez MG, Rodríguez A, Rodríguez AD, Rodríguez MH. Lethal effects of Gliocladium virens, Beauveria bassiana and Metarhizium anisopliae on the malaria vector Anopheles albimanus (Diptera: Culicidae). J Bio Sci Technol 2013; 23:1098-1109.

42. Luz C, Rocha L, Nery G. Detection of entomopathogenic fungi in peridomestic Triatomine-Infested areas in Central Brazil and fungal activity against Triatoma infestans (Klug) (Hemiptera: Reduviidae). Neotrop Entomol 2004; 33:783-791.

43. Castillo RI, Gálvez OR, Torres JL, Vázquez-Martínez MG. Control de calidad en la producción del hongo Gliocladium virens, patógeno de Anopheles albimanus (Wiedemann 1820), vector del paludismo en México. Interciencia 2013; 38:387-391.

44. Reyes-Novelo E, Ruiz-Piña H, Escobedo-Ortegón J, Barrera-Pérez M, Manrique-Saide P, Rodríguez-Vivas RI. Triatoma dimidiata (Latreille) abundance and infection with Trypanosoma cruzi in a rural community of Yucatan, Mexico. Neotrop Entomol 2013; 42:317-324.

45. Barbu C, Dumonteil E, Gourbiere S. Characterization of the dispersal of non-domiciliated Triatoma dimidiata through the selection of spatially explicit models. PLoS Negl Trop Dis 2010; 4:e777.

46. Luz C, Rocha LF, Nery GV, Magalhães BP, Tigano MS. Activity of oil-formulated Beauveria bassiana against Triatoma sordida in peridomestic areas in Central Brazil. Mem Inst Oswaldo Cruz 2004; 99:211-218.

47. Lecuona R, Clement JL, Riba G, Joulie C, Juarez MP. Spore germination and hyphal growth of Beauveria $s p$. on insect lipids. J Econ Entomol 1997; 89:119-123.

48. Forlani L, Pedrini N, Juárez MP. Contribution of the horizontal transmission of the entomopathogenic fungus Beauveria bassiana to the overall performance of a fungal powder formulation against Triatoma infestans. Res Rep Trop Med 2011; 2:135-140. 